\title{
Use of computer vision to determine leaf damage caused by Diaphania hyalinata in Santiago del Estero, Argentina
}

\author{
Ledda Inés Larcher ${ }^{1}$, Enrique Martín Biasoni², Carlos Alberto Cattaneo ${ }^{3}$, Silvia Adriana Helman ${ }^{4}$, \\ Marcelo López ${ }^{5}$
}

\begin{tabular}{ll}
\hline I N F O \\
$\begin{array}{l}\text { Received 10 May 2015 } \\
\text { Accepted 22 Jun 2015 } \\
\text { Available on-line 29 Jun 2015 } \\
\text { Responsible Editor: M. Herdon }\end{array}$ & $\begin{array}{l}\text { A B S T R A C T } \\
\text { percentages of defoliation. In this context and to determine precisely the consumed area } \\
\text { during the larval stage, we developed a method that uses computer vision techniques. } \\
\text { Programs use digitized images of the leaves before and after inserting the larvae to }\end{array}$ \\
$\begin{array}{l}\text { Keywords: } \\
\text { computer vision, image }\end{array}$ & $\begin{array}{l}\text { determine the consumed area. The programs work with binarized and thresholded images, } \\
\text { first processing the leaf without damage, then the one that presents decrease in the } \\
\text { processing, leaf damage, } \\
\text { defoliation, Diaphania } \\
\text { hyalinata. }\end{array}$ \\
$\begin{array}{l}\text { sesulting values were similar to those mentioned and measured for this specie using other } \\
\text { techniques. It is considered an important contribution for its accuracy and short time spent } \\
\text { in processing. }\end{array}$
\end{tabular}

\section{Introduction}

Our studies were done at the irrigation area of Santiago del Estero, located in North-West Argentina, where small farm producers work on diversified productive unities, locally known as "cercos", and mainly use the association corn (Zea mays L.) - butternut squash Cucurbita moschata (Duchesne ex Lam). This crop growing system is probably inherited from Central America "milpas" when Incas extended along the Pacific coast of South America. The "cerco" system refers to a complex combination of agronomic practices, crop associations and rotation sequences. Ancient in origin, the system is now practiced in ways that vary widely from one agro-environment or cultural context to another. The most fundamental components of the system are a cluster of maize, bean, and squash landraces planted in association. Several maize landraces are typically grown, some more extensively than others, each corresponding to the specific consumption practices, soil characteristics and agronomic needs of the farm and farm family (Birol, Villalba \& Smale, 2009). Milpa or cerco systems let take maximal advantage of the environmental conditions, as documented by Simmons (1986), Montes-Hernández, Merrick \& Eguiarte (2005), Letourneau (1986) and Ranere et al. (2009) inter alia.

Among the cucurbitaceae family, species of Cucurbita genre are essential in Santiago del Estero province; nevertheless plague occurrence causes damage to crops and its control is a factor of

\author{
${ }^{1}$ Ledda Inés Larcher \\ Facultad de Agronomía y Agroindustrias, Universidad Nacional de Santiago del Estero, Argentina \\ llarcher@unse.edu.ar \\ ${ }^{2}$ Enrique Martín Biasoni \\ Facultad de Agronomía y Agroindustrias, Universidad Nacional de Santiago del Estero, Argentina \\ ebiasoni@unse.edu.ar \\ ${ }^{3}$ Carlos Alberto Cattaneo \\ Facultad de Agronomía y Agroindustrias, Universidad Nacional de Santiago del Estero, Argentina \\ cacatta@unse.edu.ar \\ ${ }^{4}$ Silvia Adriana Helman \\ Facultad de Agronomía y Agroindustrias, Universidad Nacional de Santiago del Estero, Argentina \\ silhema@unse.edu.ar \\ ${ }^{5}$ Marcelo López \\ Argentina \\ ml@unse.edu.ar
}


increasing production costs (Lira Saade \& Montes-Hernández, 2005). For this reason, knowledge and management of insects of this species are important for future plantation development.

Diaphania hyalinata (L.) (Lepidoptera; Pyralidae), also known as melonworm, is mentioned as squash main plague concerning butternut squash crops. Melonworm feeds on leaves and occasionally on the flowers and surface of fruit. Summer and winter squash are its preferred hosts. High populations will defoliate plants leaving nothing but leaf veins. On less preferred hosts like cantaloupe, larvae may feed on the surface of the fruit, leading to the name rindworm (Pozo, 2003).

In the area of horticultural production in Santiago del Estero, populations occur almost every year in high number, causing considerable damage. Generally, farmers apply insecticides several times to control the plague but with low effectiveness due to bad timing. The main reason to this is lack of knowledge and/or poor information about the species biology and population behavior under the agro ecological conditions for the province.

Studying the damage caused by larvae on leaf consumption is important as it will provide helpful information to establish operating guides for plague control. Metcalf and Luckmann (1992) indicate that almost all plants can tolerate a considerable defoliation without yield reduction yet, at the same time, that tolerance varies with stage of plant growth, overall plant vigor and the adequacy of growing conditions such as temperature, moisture and soil fertility (Metcalf and Luckmann, 1992). From this, it is crucial to make quantitative studies of damage versus reduction in crop yields to establish tolerable damage thresholds.

This work aims to evaluate the area of leaf damage caused by $D$. hyalinata using computer vision techniques.

\subsection{Diaphania hyalinata $(\mathbf{L}$.}

D. hyalinata L. is commonly known as melonworm moth and occurs throughout most of Central and South America and the Caribbean.

Melonworm is restricted to feeding on cucurbits. Both wild and cultivated cucurbits may be attacked. Summer squash and the winter squash species are good hosts. Pumpkin is of variable quality as a host, probably because pumpkins have been bred from several Cucurbita species. The Cucumis species, cucumber, gerkin, and cantaloupe, are attacked but not preferred. Watermelon is a rare host.

In about 30 days the melonworm can complete its life cycle: egg, larva (total development of about 14 days), pupa and adult (butterfly)

Figure 1 shows larvae and adult D. hyalinata

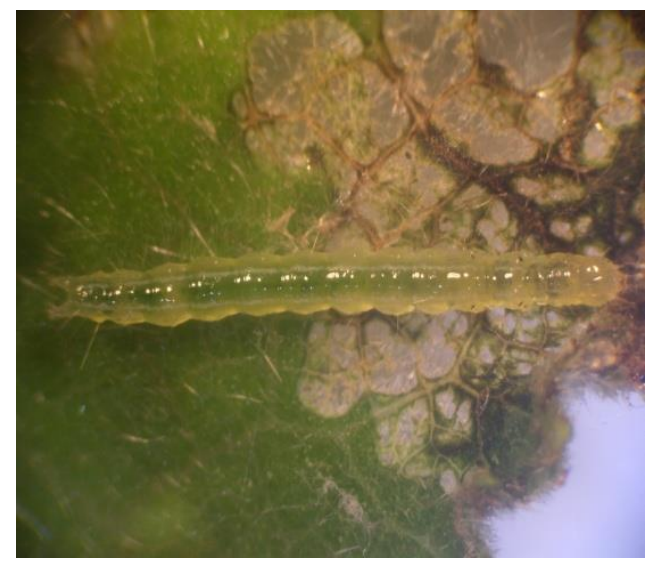

Figure 1. Larvae D. hyalinata

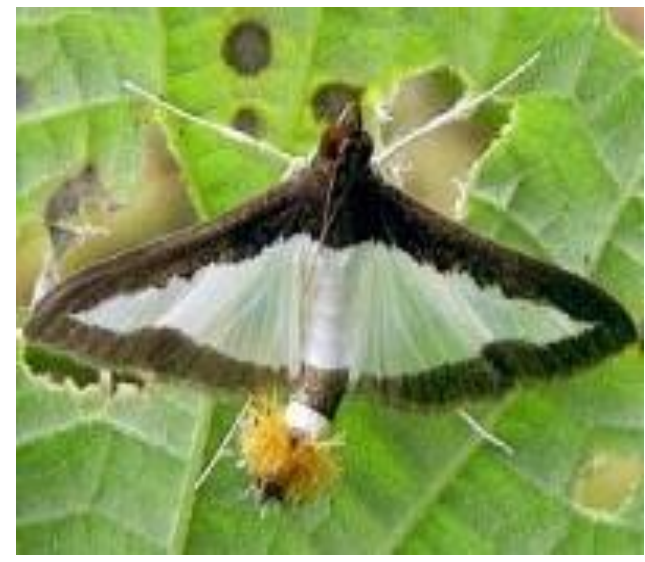

Figure 2. Adult D. hyalinata (Photo by Bob Patterson) 


\subsection{Leaf damage}

Melonworm feeds principally on foliage, especially if foliage of a favored host plant such as summer or winter squash is available. Usually the leaf veins are left intact, resulting in lace-like plant remains. However, if the available foliage is exhausted, or the plant is a less preferred species such as cantaloupe, then the larva may feed on the surface of the fruit, or even burrow into the fruit. Growers sometimes refer to these insects as "rindworms" because they cause scars on the surface of melons. In a study of melonworm damage potential to summer squash conducted in south Florida, melonworm caused a $23 \%$ yield loss due to foliage damage (indirect loss) and a 9 to $10 \%$ yield reduction due to fruit damage (direct loss) (McSorley and Waddill, 1982), Kelsheimer (1949), Capinera (2014).

Studying leaf damage is necessary as it will provide useful data for pest-management guides and policies.

In laboratory essays it was observed that leaf feeding began from the first and extended to fifth instar of $D$. hyalinata larvae, during which larvae remained hyperactive, both growth and feeding.

\subsection{Artificial vision}

Artificial vision aims to mathematically model visual perception processes and generate programs that let computers duplicate the abilities of human vision by electronically perceiving and understanding an image (Jähne and Haußecker, 2000).

Artificial vision lets automatically detect the structure and properties of a dynamic three dimensional world from bi dimensional images. These images can be monochromatic or color and can be obtained from different devices such as scanners, photographic or video cameras.

In many professional fields, including biology, technicians perform tasks that require repetitive and systematic visual analysis. Such tasks, in many cases, can be automated using artificial vision techniques. Automating these processes involves certain advantages as (a) analysis time is reduced because a computer can count thousands of items in a few seconds and (b) error is reduced, since the computer notices every object component regardless its size.

The main advantages of applying the computer vision technique include the rapid, precise, objective, efficient, consistent and non-destructive treatment, reduction of tedious and subjective human treatment, automation of mass labour-intensive operations, rapid generation of reproducible results, the ability of analyze each pixel of the surface of interest, the possibility of analyzing the whole object even if it is of small or irregular shape and of nonuniform colors and the ability of a permanent storage of any data for further analysis by keeping the picture (Kilcast, 2013).

\section{Materials and methods}

Observations were performed in cultured squash (Cucurbita moschata (Duchesne ex Lam.) (Duchesne ex Poir) in association with maize (Zea mays) located in the Campo Experimental of the University (Zanjón, Dpto. Capital of Santiago del Estero). Sowing was done in mid-January 2011. After the emergence of maize seedlings thinned was performed to achieve a density of approximately 6-7 plants per meter.

From the moment of occurrence of populations of melonworm in cultivation plots weekly monitoring were conducted; the pupae detected, 30 were collected at random and taken to the laboratory for Agricultural Zoology of the Agronomy School, where sexing was performed. Copies of each sex were placed in separate vials.

Adults (butterflies) just born were grouped in pairs, placed in wire cages lined with tulle fabric and taken to the field. Each cage was placed in a terminal bud and fixed to the floor via a bracket. Once postures were detected, daily observations were made until hatching; the newly hatched larvae were then transferred to the laboratory, placed on separate detached leaves of $C$. moschata and raised at room temperature. 
The pupae obtained in the first generation were sexed and separated to begin a second generation, which was held in brood chamber at a constant temperature of $28^{\circ} \mathrm{C}$ and $70 \% \mathrm{RH}$. Tracking method was the same as the first generation.

The eggs were placed in isolation or in groups of 2 to 3 , wherein the beam and on the underside of young leaves. The incubation period lasted approximately 3 days.

Daily consumed leaf area was measured in 8 leaves; for this, the images obtained through a binocular magnifying glass with an Olympus camera were digitized.

Leaf consumption by larvae in the first generation was $632.48 \mathrm{~mm}^{2}$. During the fourth stage was when more food is consumed, which coincides with reported by Pozo (2003). Could not determine the value for the larvae of the second generation due to decay of leaf tissue, which is why only came to evaluate area consumed until the fourth.

Initially, technicians of the laboratory for Agricultural Zoology used Image Tool 3.00 (UTHSCSA, 2002) software to measure consumed area. The method was to fill empty irregular areas of the leaf with simple geometric shapes and, by adding their areas, the foliar damage was obtained. However, the results were only approximate because overlaps as well as involuntary omissions occur. Figure 3 illustrates the procedure employed. Here, the most important limitation is that the staff assigned to the tedious task of collecting the data is capable of using the necessary instruments accurately.
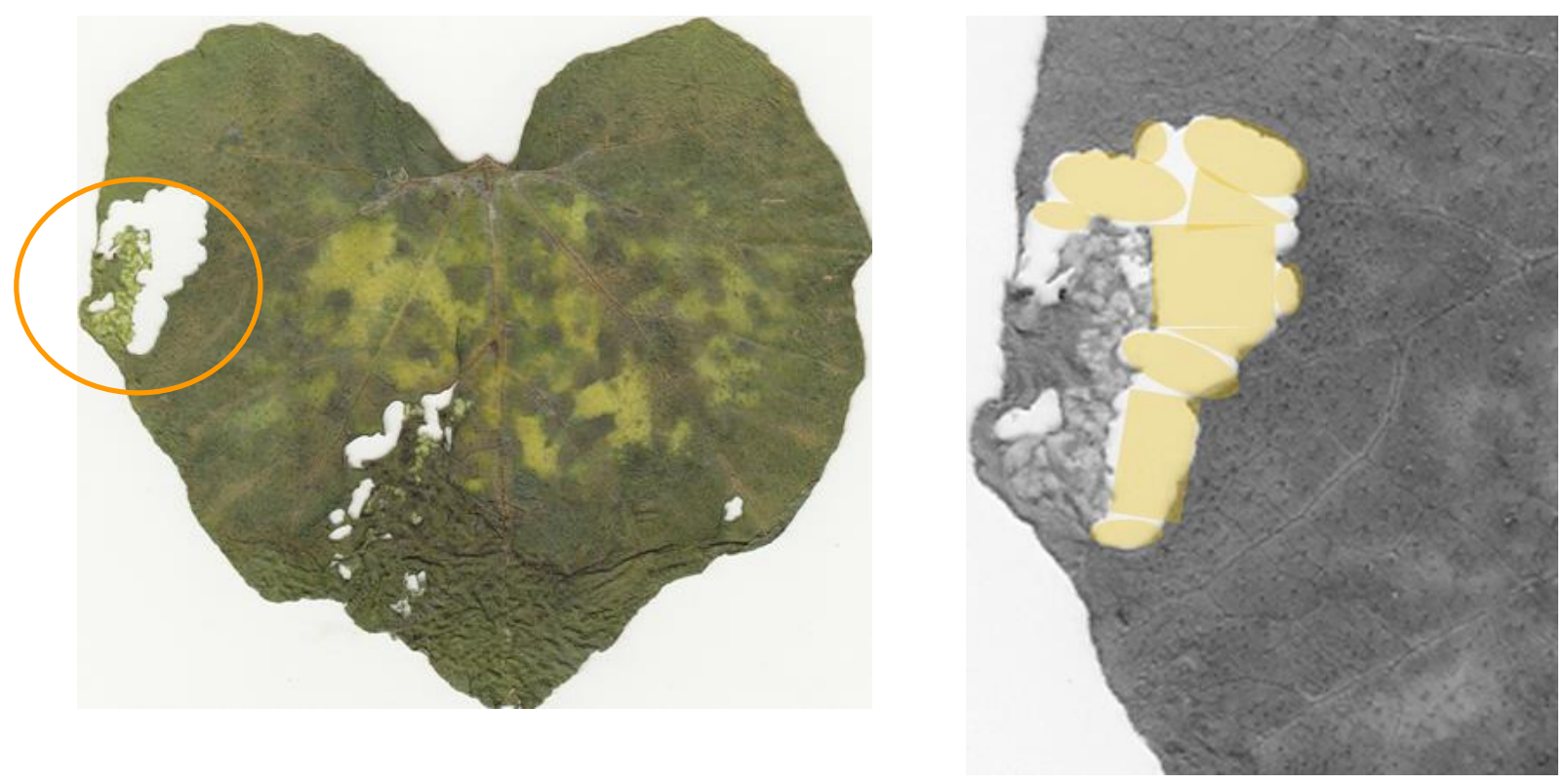

Figure 3. The result of filling empty areas with simple geometric figures shown. It can be seen that some areas are not taken into account, damaged areas overlap and, moreover, parts of the leaf which have not suffered damage have been selected

In order to get more precise results it was decided to use computer vision techniques and implement specifically designed algorithms to perform the area measurement.

Images from the leaves of $C$. moschata were digitized using a Visioneer OneTouch 8100 scanner, at constant quality (300 DPI), storing them in BMP format to avoid the distortions of compressed digitized formats. Scanned images are of variable dimension due to leaves different sizes.

A color digitized images is represented as a 3D matrix that contain values between 0 and 255 to represent colors (Figure 4). In our particular context, color information is irrelevant to the objective so the image is converted to black and white and the program works with two dimensional (2D) matrixes (Figure 5). This conversion process is called binarization and uses a threshold value to distinguish the object from the background. The resulting matrix only contains zeros (0) and one (1) values. 


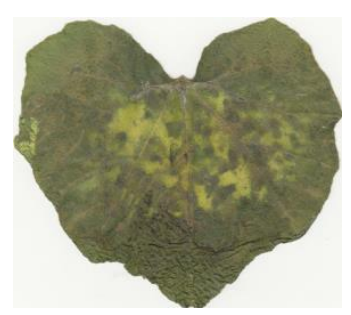

Figure 4. Color image

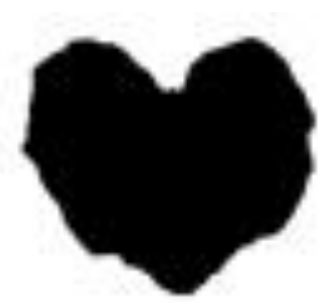

Figure 5. Binarized image

Specific algorithms were generated based on pixel neighborhood concept to determine component connection. Pixel connectivity is the way in which pixels in 2- or 3-dimensional images relate to their neighbors (Cheng, Peng \& Hwang, 2009). Our work is based in 8-connected pixels: 8-connected pixels are neighbors to every pixel that touches one of their edges or corners. These pixels are connected horizontally, vertically, and diagonally. Being $p(x, y)$ the pixel of interest, its neighbors $\left(N_{8}(p)\right)$ are $\mathrm{p}(\mathrm{x} \pm 1, \mathrm{y} \pm 1)$. Mathematically,

$$
N_{8}(p)=\left\{\begin{array}{c}
(x+1, y),(x-1, y),(x, y+1),(x, y-1),(x+1, y+1),(x+1, y-1), \\
(x-1, y+1),(x-1, y-1)
\end{array}\right\}
$$

The algorithm inspects the image pixel by pixel, examining those that have not been assigned to any object. A sequential path of the image matrix is performed and, for each pixel with value 1, its coordinates are added to a list. Using the concept of 8-neighborhood, the neighbors are inspected looking for those with value 1 to add them to the list. When finishing the verification of the pixels connected to the originally found, the coordinates of each of the pixels that form an object are stored.

A matrix $O$ is used, with changing size throughout the execution of the program. It will contain the coordinates of the pixels that make up the various objects.

A binarized digital image is represented in a matrix $I$ of $N x M$ pixels, $I$ runs element by element from left to right and from top to bottom. The neighbors' inspection is made taking corners and borders as special cases.

For each pixel $p(i, j)=1$ its coordinates are entered in a list and its 8 neighbors are inspected verifying which are connected.

Each neighbor $v(k, l)=1$ is added to matrix $O$, following pixel $p(i, j)$. At this moment, the focus will be on $v(k, l)$ and its neighbors with value 1 . As they are found, it is checked that had not previously selected and they are added to matrix $O$, becoming the new pixel of interest.

In order not to add replicated pixels, neither inspecting already checked pixels, each is nullified when incorporated to the list. The process is cyclic until no more connected neighbors are found. At this moment, a trajectory per row is stored (each, considered an object) and the row index for $O$ is increased. The algorithm returns control to the general matrix path, the index is increased and now the new pixel of interest is $p(i, j+1)$, repeating the whole process over $I$

As previously mentioned, each list element is an object. Since the program works with a matrix with values 0 or 1 , the sum of each row of the resulting array equals to the size of different objects. Flow charts of this algorithm (Figure 6) are available at http://www.cimec.org.ar/ojs/index.php/mc/article/viewFile/3955/3872 (Larcher et.al., 2011).

The program developed resulted robust, showing high efficiency in various applications, being computational time directly proportional to the object size and having a low consumption of memory. Particularly, the subprogram that performs object extraction and counting was extensively tested.

The software tool was programmed in Matlab using a PC with Intel Core 2 Quad Q8200 processor equipped with 2 GB of RAM under a 64-bit operating system. 

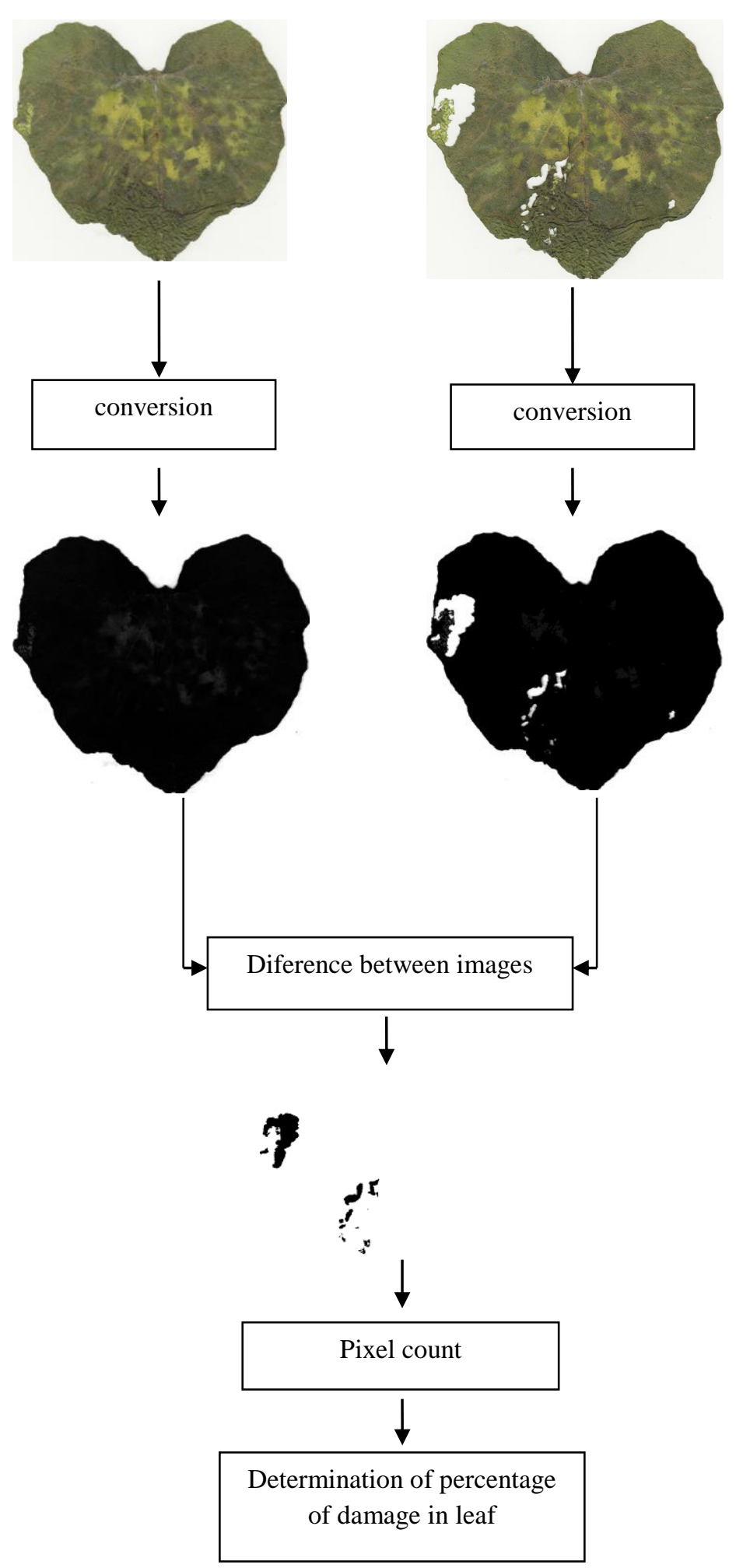

Figure 6. Flowchart for leaf damage determination

The program loads the files corresponding to the leaf when it has been just cut and when it has been already damaged then carries out the binarization using a threshold value 200. Next the area 
calculation is performed counting the pixels for each image. The difference between images corresponds to damage. The percentage of damage is obtained using equation 1:

$$
\frac{\text { damagearea }}{\text { originalarea }} * 100
$$

Next, we are showing a simplified example of how the operations are performed:

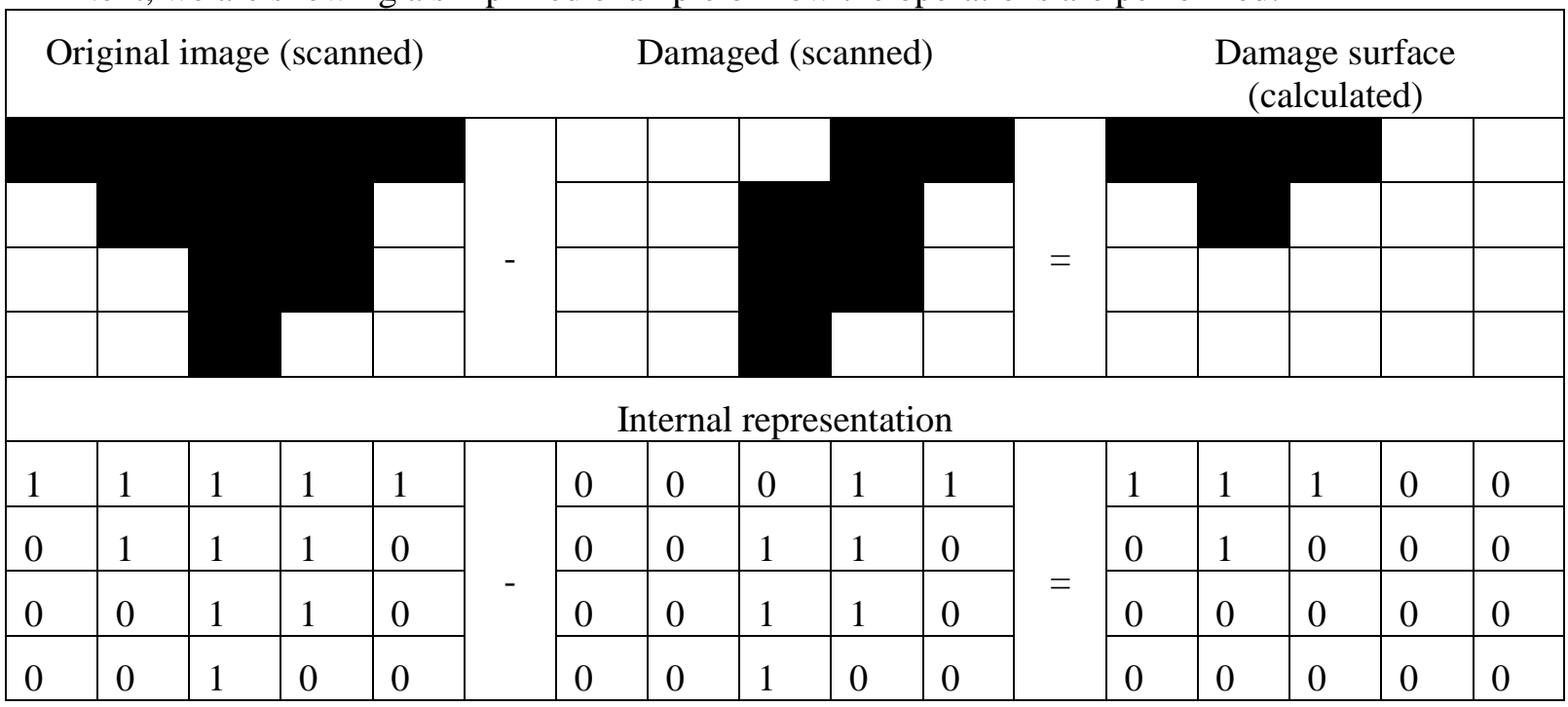

\section{Results}

To verify that the results provided by the program are accurate, a sample of known size $(5 \times 5 \mathrm{~cm} 2)$ was scanned. Then a square of $2.5 \times 2.5$ was removed. Then $(6.25 / 25) * 100$ equals a quarter of the damaged area $(25 \%)$.

\begin{tabular}{|c|c|c|c|c|c|}
\hline Complete leaf & Damage area & $\begin{array}{c}\% \\
\text { damaged } \\
\text { area }\end{array}$ & $\begin{array}{c}\text { Image size } \\
\text { (pixels) }\end{array}$ & $\begin{array}{c}\text { Execution } \\
\text { time } \\
\text { (seconds) }\end{array}$ \\
\hline & & & 2.77 & $316 \times 360$ & 0.72 \\
\hline
\end{tabular}

\section{Conclusions}

Using computer vision techniques, a software tool has been developed that accurately responds to the requirement of measuring damaged leaf area. 
The program has low computational cost. From the point of view of memory requirements, depends on the size of the images that are input for the analysis, whereas from the standpoint of computational time, it is observed a good performance.

The program has proved to be efficient and reliable and therefore, offer the possibility of designing inspection systems for the automatic measurement of foliage destroy by D. hyalinata. On the basis of digital image process algorithms, computer vision had the ability of reducing dependence on human graders increasing high quality throughput, reducing processing time and errors, improving results consistency and enhancing confidence in the safety and quality of such results. Thus, using the program will help establish guidelines for managing the population of D. hyalinata.

The result of the program is measured in pixels. From this result and calculating the relationship "pixel-image density" could be possible to transform the result to square centimeters or any other unit of measurement.

As a final note it must be remarked that we worked only with detached leaves and, as Benjamin, Freeman \& Brown (1968) stated, "Techniques for estimating leaf areas vary greatly in instrumentation depending upon whether the leaves to be measured may be detached from the living plant and whether simplicity and rapidity of measurement are required" we are aware that the image capturing as well as the image segmentation stages will require further improvement to be useful in the crop fields.

\section{References}

Birol, E., Villalba, E. R., \& Smale, M. (2009) Farmer preferences for milpa diversity and genetically modified maize in Mexico: a latent class approach. Environment and Development Economics, 14(4), 521. doi: $10.1017 / \mathrm{s} 1355770 \times 08004944$

Montes-Hernández, S., Merrick, LC \& Eguiarte, L. (2005) Maintenance of Squash (Cucurbita spp.) Landrace Diversity by Farmers' Activities in Mexico. Genetic Resources and Crop Evolution. Volume 52, Issue 6, pp 697707. DOI 10.1007/s10722-003-6018-4

Simmons, AH. (1986) New Evidence for the Early Use of Cultigens in the American Southwest. American Antiquity, Vol. 51, No. 1 pp. 73-89. Online: http://www.jstor.org/stable/280395 doi: 10.2307/280395

Letourneau, D. K. (1986) Associational Resistance in Squash Monocultures and Polycultures in Tropical Mexico. Environmental Entomology, 15 (2) 285-292; doi: 10.1093/ee/15.2.285

Ranere, AJ; Piperno, DR; Holst, I; Dickau, R \& Iriarte, J. (2009) The cultural and chronological context of early Holocene maize and squash domestication in the Central Balsas River Valley, Mexico. Vol 106, №13, 50145018. Proceedings of the National Academy of Sciences of the United States of America. doi: 10.1073/pnas.0812590106

Benjamin, D.M; Freeman, G.H. \& Brown, E.S. (1968) The determination of irregularly -shaped areas of leaves destroyed by chewing insects. Ann. appl. Biol., 61(1), 13-17. doi: 10.1111/j.1744-7348.1968.tb04505.X

Jähne, B \& Haußecker, H. (2000) Computer Vision and Applications, A Guide for Students and Practitioners. Academic Press.

Capinera, J. (2014) University of Florida, Publication Number: EENY-163 Publication. (On line) http://entnemdept.ufl.edu/creatures/veg/leaf/melonworm.htm (accessed 20/02/15)

Kelsheimer, EG. (1949) Control of insect pests of cucumber and squash. Florida Agricultural Experiment Station Bulletin 465.15 pp.

Kilcast, D. (2013) Instrumental Assessment of Food Sensory Quality: A Practical Guide. Elsevier. 658p. (On line) http://www.sciencedirect.com/science/book/9780857094391 (Accessed 20-03-15) doi: $10.1533 / 9780857098856$

Cheng, CC; Peng, GJ \& Hwang, WL (2009) "Subband weighting with Pixel Connectivity for 3-D wavelet coding", IEEE transactions on image processing : a publication of the IEEE Signal Processing Society 18 (1): 52-62, doi: 10.1109/tip.2008.2007067

Larcher, L., Biasoni E., Cattaneo C., Ruggeri A. \& Herrera A. C. (2011) Algoritmo para detección de bordes y ulterior determinación de objetos en imágenes digitales. Mecánica Computacional, Vol XXX, 2841-2852 (On line) http://www.cimec.org.ar/ojs/index.php/mc/article/viewFile/3955/3872 (Accessed 20-03-15) 
McSorley R \& Waddill VH. (1982) Partitioning yield loss on yellow squash into nematode and insect components. Journal of Nematology 14(1): 110-118.

Metcalf, R. \& Luckmann, W. (1992) Introducción al manejo de plagas de insectos. Ed. Limusa. México.

Metcalf, R. \& Luckmann, W. (1994) Introduction to insect pest management, 3rd edn. John Wiley and Sons, Inc., New York.

Pozo, E. (2003) Consumo de alimento por larvas de Diaphania hyalinata (L) (Lepidoptera; Pyralidae). Rev. Protección Veg. 18 (2): 104-107.

UTHSCSA Image Tool 3.0. Wilcox, CD; Dove, SB; McDavid, W. \& Greer, D. Department of Dental Diagnostic Science, University of Texas Health Science Center, San Antonio, Texas. Available at http://compdent.uthscsa.edu/dig/download.html

Lira Saade, R.\& Montes Hernandez, S. (2005) Agricultura en Mesoamérica. Curcubitas (Cucurbita spp) in “Cultivos marginados. Otra perspectiva de 1492”. Eds. Hernández Bermejo, JE \& León, J. Colección FAO: producción y protección vegetal, Number 26) FAO 1992, Italy (On line) http://www.fao.org/docrep/018/t0646s/t0646s.pdf; (Accessed 21-04-15).

Smith, RI. (1911) Two important cantaloupe pests. North Carolina Agricultural Experiment Station Bulletin 214: 101-146.

Smith H.A, Capinera J.L., Pena J.E \& Linbo-Terhaar B. (1994) Parasitism of pickleworm and melonworm (Lepidoptera: Pyralidae) by Cardiochiles diaphaniae (Hymenoptera: Braconidae). Environmental Entomology 23(5): 1283-1293. doi: 10.1093/ee/23.5.1283 